\title{
Factors influencing the distribution of arsenic, fluorine and iodine in shallow groundwater in the oasis zone in the southern margin of the Tarim Basin in Xinjiang, P. R. China
}

\author{
Wei Fan $^{1,2}$, Jinlong Zhou ${ }^{1,2, *}$, Yinzhu Zhou ${ }^{3, * *}$, Yanyan Zeng ${ }^{1,2}$, and Yunfei Chen $^{1,2}$ \\ ${ }^{1}$ College of Water Conservancy and Civil Engineering, Xinjiang Agricultural University, Urumqi, \\ 830052, P.R.China \\ ${ }^{2}$ Xinjiang Hydrology and Water Resources Engineering Research Center, Urumqi, 830052, P.R.China \\ ${ }^{3}$ Key Laboratory of Drinking Water Science and Technology, Research Center for Eco- \\ Environmental Sciences, Chinese Academy of Sciences, Beijing 100049, P.R.China
}

\begin{abstract}
Test results on 302 shallow groundwater samples in an oasis zone in the southern margin of the Tarim Basin in Xinjiang were collected and analysed for a large number of chemical parameters and subjected to mathematical statistics methods. Results show that groundwater with high arsenic, fluorine and iodine concentrations were mainly distributed in the Minfeng County in the central part of the study area. Shallow groundwater in the southern margin of the entire Tarim Basin generally had high fluorine concentrations. The distribution of arsenic and fluorine in groundwater were similar. Intensive evaporation under the arid climatatic condition was an important factor for the enrichment of arsenic, fluorine and iodine in groundwater.
\end{abstract}

\section{Introduction}

Natural genesis of high arsenic (As), fluorine (F) or iodine (I) in groundwater have been reported in many areas of northern China, such as Songnen Plain, Hetao Plain, and Datong Basin [1-4]. Migration and transformation of groundwater arsenic, fluorine and iodine vary with the variation of hydrogeochemical conditions. Endemic arsenicosis, fluorosis and iodism seriously threaten human health [5].In China, the limits for As, F and I in drinking water are $10 \mu \mathrm{g} / \mathrm{L}, 1.0 \mathrm{mg} / \mathrm{L}$ and $0.08 \mathrm{mg} / \mathrm{L}$, respectively [4]. The enrichment of groundwater As, F and I in parts of Xinjiang Uygur Autonomous Region (hereinafter referred to as "Xinjiang") is a threat to the health of local residents [6-8]. However, there is no research on the coexistence of groundwater As, F and I in the southern margin of the Tarim Basin. The southern margin of the Tarim Basin is located in the south of Xinjiang. It extends from Moyu County in Hotan district in the west to the Ruoqiang County in Bayinguoling Mongolian Autonomous Prefecture, which is adjacent to the Taklimakan

\footnotetext{
*Corresponding author: zizhouj1@163.com

** Correspondence to: yinzhu_zhou@qq.com (YZ Zhou)
} 
Desert in the north and the piedmont line of Kunlun Mountain in the south. It is always windy and dusty in this area with an extreme climate. The annual average precipitation varies between 17.4 and $48.2 \mathrm{~mm}$ (which decreases gradually from west to east), while the annual evaporation can reach up to 2450 to $2900 \mathrm{~mm}$. The annual average temperature ranges between 10 and $12^{\circ} \mathrm{C}$, with annual temperature range generally ranges between 30 and $35^{\circ} \mathrm{C}$. Groundwater is the only drinking water source.

302 shallow groundwater samples were collected in the oasis zone of the southern margin of Tarim Basin (Moyu County-Ruoqiang County) from 2014 to 2017. The chemical indexes, including $\mathrm{pH}$, Eh, total hardness, TDS, $\mathrm{K}^{+}, \mathrm{Na}^{+}, \mathrm{Ca}^{2+}, \mathrm{Mg}^{2+}, \mathrm{Cl}^{-}, \mathrm{SO}_{4}{ }^{2-}, \mathrm{HCO}_{3}^{-}, \mathrm{F}^{-}$, As, $\mathrm{I}^{-}$, total dissolved $\mathrm{Fe}$ and $\mathrm{Mn}$, etc, were determined at the Mineral Water Testing Center of the Institute of Hydrogeology and Environmental Geology, Chinese Academy of Geological Sciences. The distribution of sampling points is shown in Fig. 1. In this manuscript, we use the above test data to investigate the distribution of arsenic, fluorine, and iodine in shallow groundwater from the southern margin of the Tarim Basin. We use hydrogeochemical and mathematical statistics methods in our data interpretations. Moreover, the causes of enrichment of groundwater with these elements are discussed. The causes discussed provided a theoretical basis for promoting the construction of new rural areas that can be provided with good and safe drinking water.

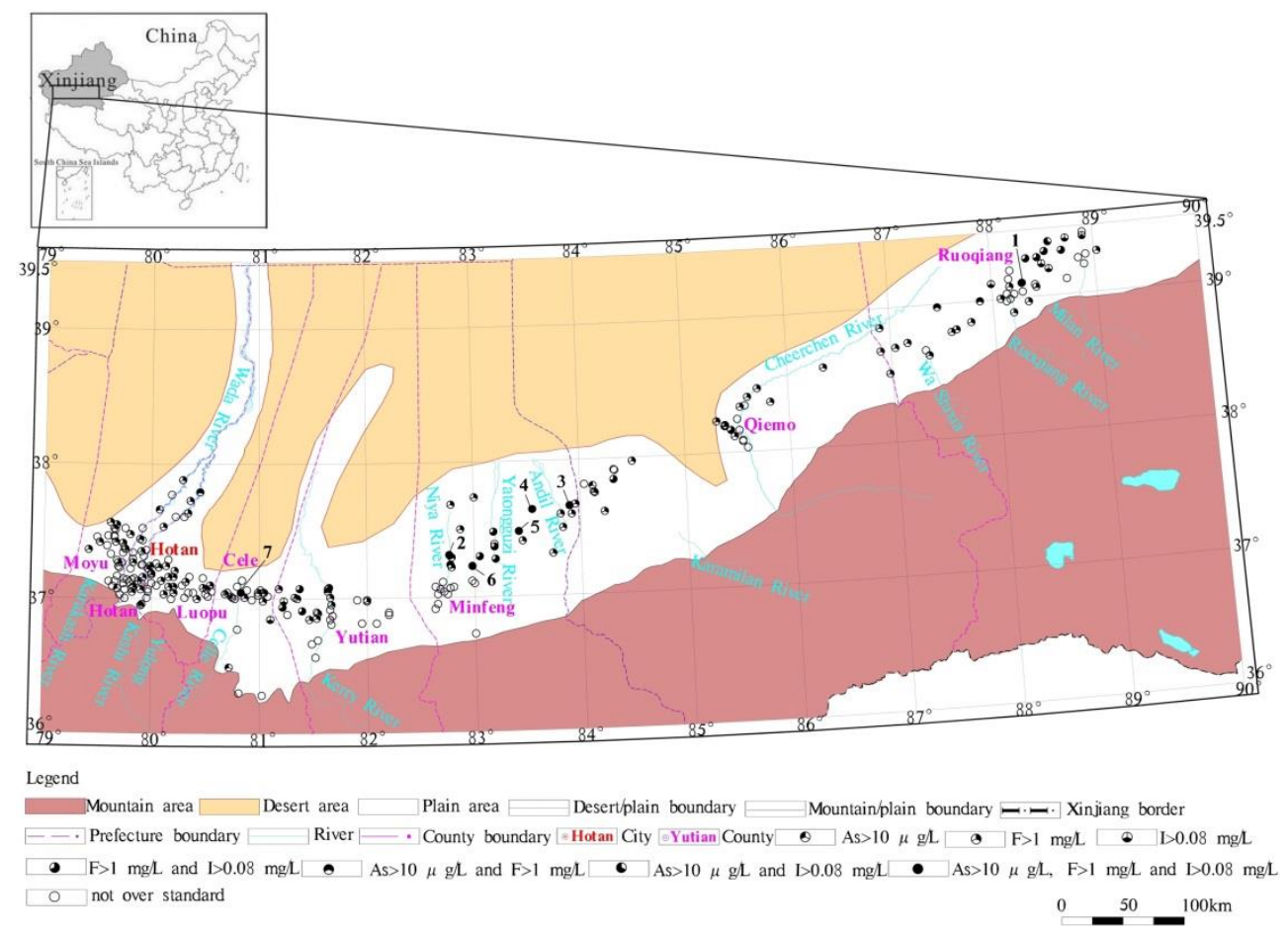

Fig. 1. Location map showing distribution of Sampling Points.

\section{Geological and hydrogeological conditions}

The terrain in the study area is high in the southwest and low in the northeast. The landform can be divided into four types from south to north, including the piedmont zone and hilly zone, the piedmont proluvial-alluvial inclined plain area, the alluvial fan-fringe area, and the desert and lacustrine plain area. Phreatic aquifer of alluvial slope plain in the south is 
constituted of homogeneous gravel. Unconfined groundwater of alluvial plain in the middle part is constituted of gravel, medium coarse sand, fine sand, sub-sand and sub-clay interlayers. Confined groundwater of deserts flood plains is distributed in the north. Multilayer aquitard gradually formed with decreased particle sizes from south to north. Groundwater mainly recharged by penetration of river water, canal water and field irrigation water, then recharged by bedrock fissure water laterally in mountainous areas. Groundwater runoff was generally from south to north. Groundwater mainly discharged by artificial exploitation, lateral runoff and phreatic water evaporation and transpiration [9].

\section{Results and discussion}

\subsection{Groundwater arsenic, fluorine and iodine distribution}

Groundwater As concentration ranged between 0.5 and $91.2 \mu \mathrm{g} / \mathrm{L}$ (with an average of 5.74 $\mu \mathrm{g} / \mathrm{L}$ ) in shallow groundwater in the study area. Among all the groundwater samples, $6.3 \%$ of which had an arsenic concentration greater than $10 \mu \mathrm{g} / \mathrm{L}$, the satandard limit. High arsenic groundwater (As $>10 \mu \mathrm{g} / \mathrm{L}$ ) was mainly distributed in the center and northeast of the study area, which was close to the Minfeng County and Ruoqiang County, respectively. The groundwater had a generally high fluorine concentration $(0.05$ to $28.3 \mathrm{mg} / \mathrm{L})$. The average fluoride concentration in the groundwater was $1.75 \mathrm{mg} / \mathrm{L}$ (greater than fluoride limit of $1.0 \mathrm{mg} / \mathrm{L}$ in Class III water according to the National Groundwater Quality Standard GB/T 14848-2017). High fluoride groundwater ( $>1.0 \mathrm{mg} / \mathrm{L})$ was mainly distributed in the centre of the study area. The iodine concentration ranged between 0 and $2.64 \mathrm{mg} / \mathrm{L}$, with an average of $0.06 \mathrm{mg} / \mathrm{L}$ (less than the Class III water standard of 0.08 $\mathrm{mg} / \mathrm{L})$. High iodine groundwater (I $>0.5 \mathrm{mg} / \mathrm{L}$ ) was mainly distributed in the northeastern part of the study area and the north of Ruoqiang County. High As, F and I groundwater samples accounted for $2.3 \%$ of the total (Table 1 ).

Table 1.Chemistry parameters of high As, F and I groundwater samples.

\begin{tabular}{cccccccc}
\hline No & 1 & 2 & 3 & 4 & 5 & 6 & 7 \\
\hline Location & Ruoqiang & Minfeng & Minfeng & Minfeng & Minfeng & Minfeng & Cele \\
F- $(\mathrm{mg} / \mathrm{L})$ & 2.4 & 11.8 & 2.8 & 23.2 & 17.0 & 6.8 & 5.4 \\
$\mathrm{As}(\mu \mathrm{g} / \mathrm{L})$ & 67.6 & 19.0 & 91.2 & 24.2 & 18.5 & 42.1 & 14.0 \\
$\mathrm{I}(\mathrm{mg} / \mathrm{L})$ & 0.32 & 0.25 & 0.73 & 0.47 & 0.21 & 0.18 & 0.12 \\
\hline
\end{tabular}

\subsection{Occurrence and environmental conditions of arsenic, fluorine and iodine in groundwater}

The form and migration of ions in the environment were greatly affected by $\mathrm{pH}$ values [4]. The groundwater with high As, F and I concentrations in the study area occurred under weak alkaline environment with $\mathrm{pH}$ values ranged between 7 and 9, this can promote the enrichment of arsenic, fluorine and iodine. The $\mathrm{pH}$ value had a positive correlation with groundwater As, F and I concentrations (Fig.2 a, b and c).With the increase of pH value, adsorption of groundwater arsenate and arsenite on positively charged colloids and clay minerals reduced, which lead to the increase of groundwater As. Previous studies showed that As concentration in shallow groundwater in the Tarim Basin is related to reductive dissolution of Fe(III) oxides [6]. High TDS (ranged between 199 and $358694 \mathrm{mg} / \mathrm{L}$, with an average of $11532 \mathrm{mg} / \mathrm{L}$ ) and $\mathrm{pH}$ values in groundwater in the study area lead to the reduce 
of $\mathrm{Ca}^{2+}$ ion activity, which inhibit the formation of $\mathrm{CaF}_{2}$ and promote the enrichment of groundwater [10]. Under weak alkaline conditions, $\mathrm{I}^{-}$adsorbed on the sediment will migrate to groundwater, which indirectly promotes the enrichment of groundwater I [11]. High As and $\mathrm{F}$ groundwater had relatively low $\mathrm{SO}_{4}{ }^{2-}$ and $\mathrm{NO}_{3}{ }^{-}$concentrations, indicating that reducing environment can promote groundwater As and $\mathrm{F}$ enrichment [12].The correlations among groundwater As, F and I concentrations were shown in Fig. 2, in the study area, for those groundwater samples had relatively high $\mathrm{F}(>5 \mathrm{mg} / \mathrm{L})$, positive correlations between As and F, I and F, as well as As and I were observed (Fig.2 d, e and f).
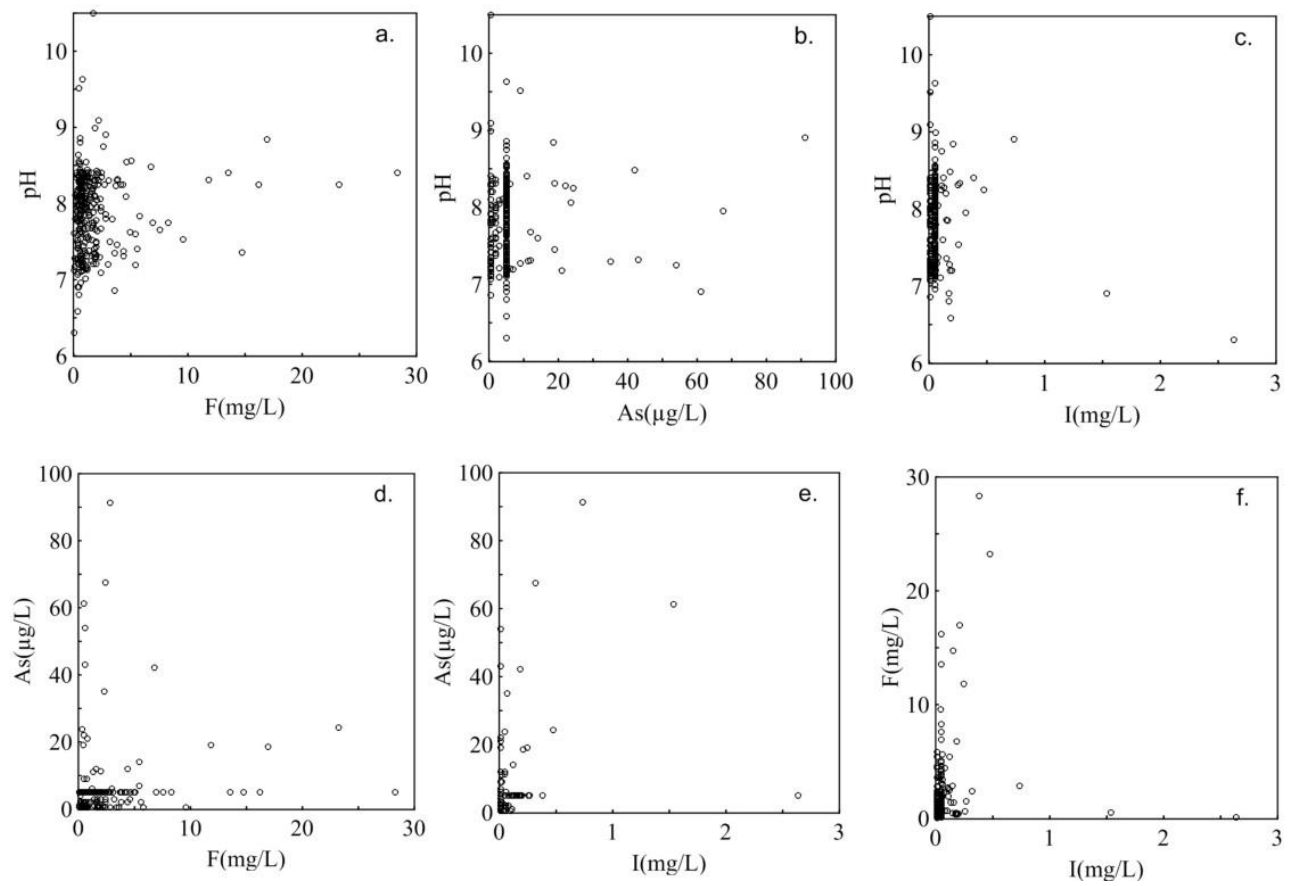

Fig.2. Relationships between (a) $\mathrm{pH}$ and F, (b)pH and As, (c)pH and I (d)As and F (e)As and I (f)F and I concentration in groundwater.

The research was funded by the National Natural Science Foundation of China (NSFC) project 'Research on Groundwater Salinization Mechanism in Kashgar Area of Xinjiang' (41662016)and the Central Government's fund project of returning two-right payment "1:250,000 Land Quality Geochemical Survey (S15-1-LQ) in Hotan-Ruoqiang Oasis Zone, Xinjiang".

\section{References}

1. B Zhang, M Hong, Y.S Zhao, X.Y Lin, X.L Zhang, J Dong, Envir. Geoch. and Heal., 25 (2003)

2. J.M Bian, J Tang, L.S Zhang, H.Y Ma, J Zhao, Jour. of Geoch. Exp., 112 (2012)

3. H.M Guo, Y Zhang, L.N Xing, Y.F Jia, Appl. Geoch., 27 (2012)

4. K.F Pi, Y.X Wang, X.J Xie, C.L Su, T Ma, J.X Li, Y.Q Liu, J Hazard Mater, 300(2015)

5. G.W Dong, C.Z Fu, Y.ZEr, W Cheng, B.H Shuang, Z Yan, J Geochem Explor, 135 (2013)

6. Y.Z Zhou, Y.Y Zeng, J.L Zhou, H.M Guo, Q Li, R.L Jia, Y.F Chen, J.T Zhao, Applied Geochemistry, 77 (2017) 
7. Y.F Jia, B.D Xi, Y.H Jiang, H.M Guo, Y Yang, X.Y Lian, S.B Han, Science of the Total Envir., 643 (2018)

8. Y.Y Zeng, Y.Z Zhou, J.L Zhou, R.L Jia, J.C Wu, Expos. and Health, 10 (2018)

9. X.H Teng, Z.G Zhang, W.X Han, Y.H Fang, C.C Ye, Acta Sedimen.a Sinica, 33, 5 (2015) (in Chinese)

10. Q Guo, H.M Guo, Y.CYang, S.B Han, F.C Zhang,J. Hydrol, 518 (2014)

11. X.B Xue, J.X Li, K Qian, X.J Xie, Earth Science, 43 (2018)(in Chinese)

12. Q Guo, H.M Guo, Procedia Eatrh and Planetary Science, 7 (2013) 